\title{
Article \\ Rapid Preparation of Fluorescent Carbon Dots from Pine Needles for Chemical Analysis
}

\author{
Hweiyan Tsai ${ }^{1,2}$, Kaiying Chang ${ }^{3}$, Wanshing Lee $^{3}$ and C. Bor Fuh ${ }^{3, *(1)}$ \\ 1 Department of Medical Applied Chemistry, Chung Shan Medical University, Taichung 402, Taiwan; \\ annetsai@csmu.edu.tw \\ 2 Department of Medical Education, Chung Shan Medical University Hospital, Taichung 402, Taiwan \\ 3 Department of Applied Chemistry, National Chi Nan University, Puli, Nantou 545, Taiwan; \\ s108324501@mail1.ncnu.edu.tw (K.C.); s108324902@mail1.ncnu.edu.tw (W.L.) \\ * Correspondence: cbfuh@ncnu.edu.tw; Tel.: +886-49-2919-779; Fax: +886-49-2917-956
}

check for updates

Citation: Tsai, H.; Chang, K.; Lee, W.; Fuh, C.B. Rapid Preparation of Fluorescent Carbon Dots from Pine Needles for Chemical Analysis. Nanomaterials 2022, 12, 66. https:// doi.org/10.3390/nano12010066

Academic Editors: Constantine D. Stalikas and Hideya Kawasaki

Received: 26 November 2021 Accepted: 25 December 2021 Published: 28 December 2021

Publisher's Note: MDPI stays neutral with regard to jurisdictional claims in published maps and institutional affiliations.

Copyright: (C) 2021 by the authors. Licensee MDPI, Basel, Switzerland. This article is an open access article distributed under the terms and conditions of the Creative Commons Attribution (CC BY) license (https:// creativecommons.org/licenses/by/ $4.0 /)$.

\begin{abstract}
Fluorescent carbon dots with blue, green, and red emissions were rapidly prepared from modified pine needles through microwave irradiation in a one-pot reaction. The fluorescence intensity and emission versatility for a carbon source were experimentally optimized. The reaction times were under $10 \mathrm{~min}$ and the reaction temperatures were lower than $220^{\circ} \mathrm{C}$. Potential applications of magnetic fluorescence-linked immunoassays of carcinoembryonic antigen (CEA) and tumor necrosis factor-alpha (TNF- $\alpha$ ) were presented. The detection limits for CEA and TNF- $\alpha\left(3.1\right.$ and $2.8 \mathrm{pg} \mathrm{mL}{ }^{-1}$, respectively) are lower than those presented in other reports, whereas the linear ranges for CEA and TNF- $\alpha$ (9 $\mathrm{pg} \mathrm{mL}^{-1}$ to $18 \mathrm{ng} \mathrm{mL}^{-1}$ and $8.5 \mathrm{pg} \mathrm{mL}^{-1}$ to $17 \mathrm{ng} \mathrm{mL}^{-1}$, respectively) are wider than those presented in other reports. Magnetic immunoassays with fluorescent $\mathrm{CD}_{\mathrm{s}}$ prepared from pine needles can enable rapid, sensitive, and selective detections for biochemical analysis.
\end{abstract}

Keywords: carbon dots; pine needles; chemical analysis; carcinoembryonic antigen; tumor necrosis factor-alpha

\section{Introduction:}

In general, carbon dots $\left(\mathrm{CD}_{\mathrm{s}}\right)$ are carbon nanoparticles with a size of less than $10 \mathrm{~nm}$. Carbon dots have optical, electrical, and chemical properties suitable for various applications [1-7]. Fluorescent $\mathrm{CD}_{\mathrm{s}}$ are widely used in numerous chemical, biochemical, and environmental applications because of their hydrophilicity, biocompatibility, biodegradability, and stability features with respect to organic dyes and inorganic quantum dots.

The fluorescence properties of $\mathrm{CD}_{\mathrm{s}}$ depend on their synthesis procedure and the precursors used in their preparation. Most $C D_{s}$ display blue fluorescence and some $C D_{s}$ exhibit green fluorescence. Green carbon sources can be used to produce widely available, cost-effective, and ecologically friendly $\mathrm{CD}_{\mathrm{s}}$. Green carbon precursors have gained wide popularity in scientific worlds to support sustainable environments. Thus, developing a simple, rapid, green, and economical method for synthesizing $\mathrm{CD}_{\mathrm{s}}$ with various emission wavelengths for optical sensing is crucial.

Pine needles come from pinus morrisonicola (five-leaf pines) which are grown in the mountainous regions of Taiwan at elevations of $300-2300 \mathrm{~m}$. Pine needle-related products are used in dietary supplements and have potential antioxidative, antitumor, and antibacterial functions [8-11]. Pine needles are green carbon sources with high potentials for use in producing fluorescent $\mathrm{CD}_{\mathrm{s}}$ with various emission wavelengths. Microwave heating is a homogeneous, efficient, cost-effective, and scalable heating method with a short reaction time. Microwave-assisted synthesis on nanomaterials is eco-friendly and has become popular in scientific research $[12,13]$. Herein, fluorescent $C_{\mathrm{s}}$ with various emission wavelengths were rapidly prepared from modified pine needles through microwave irradiation. 
Biomarker detections have been used as an essential reference for the early diagnosis of cancer-related diseases and for monitoring the progress of medical treatments $[14,15]$. Currently, the enzyme-linked immunosorbent assay (ELISA) is the most commonly used biomarker detection approach; however, it is highly labor-intensive and time-consuming. Magnetic immunoassays with functional nanoparticles have been reported to provide higher detection speed and detection sensitivity than does ELISA [16-19]. Magnetic nanoparticles of iron oxides can provide a fast reconcentration of immunocomplexes after reaction and washing. Magnetic immunoassays with functional $\mathrm{CD}_{\mathrm{s}}$ were employed for biomarker detection to demonstrate the potential applications. Herein, carcinoembryonic antigen (CEA) and tumor necrosis factor-alpha (TNF- $\alpha$ ) were used as representative biomarkers.

\section{Experimental Method}

\subsection{Materials}

Tetraethoxysilane (TEOS), ethylenediamine ( $\geq 99 \%)$, phosphoric acid ( $\geq 85 \%)$, 3-amino propyl triethoxysilane $(\geq 99 \%)$, cetyltrimethylammonium bromide (CTAB, $\geq 98 \%)$, 1-ethyl3-(3-dimethyl aminopropyl) carbodiimide (EDC, $\geq 98 \%$ ), N-hydroxysuccinimide (NHS, $\geq 99 \%$ ), CEA, and monoclonal and polyclonal anti-CEA, were purchased from SigmaAldrich (St. Louis, MO, USA). TNF- $\alpha$ and anti-TNF- $\alpha$ were acquired from Fitzgerald Industries International (Aton, MO, USA). Sera samples were supplied by Jackson Immunoresearch (West Grove, CA, USA), and ferrous and ferric chlorides $\left(\mathrm{FeCl}_{2} 4 \mathrm{H}_{2} \mathrm{O}, \mathrm{FeCl}_{3}\right.$ $6 \mathrm{H}_{2} \mathrm{O}$ ) were obtained from J. T. Baker (Philipsburg, NJ, USA). Double distilled deionized water was from Milli-Q (Fremont, CA, USA) with a resistivity of $18.2 \mathrm{M} \Omega \cdot \mathrm{cm}$. The microwave instrument was purchased from Milestone (ETHOS UP, Sorisole, Italy). The UV-vis spectrometer was from Agilent Scientific (HP8450, Santa Clara, CA, USA), the FTIR was from Perkin Elmer (Spectrum 2, Waltham, MA, USA), the TEM was from Joel (JEL 1400, Tokyo, Japan), and the superconducting quantum interference device (SQUID) magnetometer was from Quantum Design (San Diego, CA, USA).

\subsection{Preparation of Functional Nanoparticles}

Pine needles were collected from the university campus of National Chi Nan University at Puli, Nantou, Taiwan. They were then washed with water, air-dried, placed in an oven at $60{ }^{\circ} \mathrm{C}$ for $1.5 \mathrm{~h}$, cut into small pieces, and ground into fine powder. The powder was stored in a dry box for further use.

Three types of $C D_{s}\left(C D_{b}, C D_{g}\right.$, and $\left.C D_{r}\right)$ were prepared through a one-pot microwave reaction by using the pine needle powder as the main carbon source. The reaction temperature and reaction time of the microwave were optimized to obtain the fluorescence wavelength and intensity. The ranges of temperature were 160 to $220{ }^{\circ} \mathrm{C}$ for $\mathrm{CD}_{\mathrm{b}}$ and $\mathrm{CD}_{\mathrm{g}}$ and extended down to $40{ }^{\circ} \mathrm{C}$ for $\mathrm{CD}_{\mathrm{r}}$. The ranges of running time were from 5 to $20 \mathrm{~min}$. $\mathrm{CD}_{\mathrm{b}}$ was prepared by placing a mixture of $0.1 \mathrm{~g}$ of needle powder, $0.2 \mathrm{~mL}$ of ethylenediamine, $1 \mathrm{~mL}$ of phosphoric acid, and $10 \mathrm{~mL}$ of distilled water in a microwave at $220{ }^{\circ} \mathrm{C}$ for $10 \mathrm{~min}$. Next, the mixture was centrifuged at $8000 \mathrm{rpm}$ for $15 \mathrm{~min}$ by using a membrane tube with a molecular weight cutoff of $3000 \mathrm{MW}$. The upper part of the mixture was collected, vacuum dried, and stored for further use. $\mathrm{CD}_{\mathrm{g}}$ was prepared through the same procedure as was $\mathrm{CD}_{\mathrm{b}}$, except that no phosphoric acid was added to the mixture before the microwave reaction. $C D_{\mathrm{r}}$ was prepared by mixing $0.1 \mathrm{~g}$ of needle powder with $10 \mathrm{~mL}$ of ethanol and placing the mixture in a microwave at $50{ }^{\circ} \mathrm{C}$ for $5 \mathrm{~min}$. The solution was centrifuged at $8000 \mathrm{rpm}$ for $15 \mathrm{~min}$ by using a membrane tube with a molecular weight cutoff of $1000 \mathrm{MW}$. The upper part of the solutions was collected, vacuum dried, and stored for further use. The concentrations of fluorescent and UV-vis measurement in PBS were $1 \mathrm{mg} \mathrm{mL}^{-1}$ and $0.1 \mathrm{mg} \mathrm{mL}^{-1}$, respectively. The quantum yield (QY) was calculated based on the following equation. $\mathrm{QY}_{\mathrm{C}}=\mathrm{QY}_{\mathrm{S}} \times\left(\mathrm{I}_{\mathrm{C}} / \mathrm{I}_{\mathrm{S}}\right) \times\left(\mathrm{A}_{\mathrm{S}} / \mathrm{A}_{\mathrm{C}}\right) \times\left(\mathrm{N}_{\mathrm{c}}{ }^{2} / \mathrm{N}_{\mathrm{S}}{ }^{2}\right)$. Where $\mathrm{QY}$ is the quantum yield, the subscripts " $c$ " and " $s$ " refer to $C D_{s}$ and standard, respectively. $I$ is the integrated area in the emission spectrum and A is the absorbance at 320 and 410 nm wave- 
length. Quinine sulfate ( $Q Y_{\mathrm{S}}=54 \%, \mathrm{~N}_{\mathrm{s}}=1.33$ in $0.1 \mathrm{M} \mathrm{H}_{2} \mathrm{SO}_{4}$ solution) and Rhodamine $6 \mathrm{G}\left(\mathrm{QY}_{\mathrm{s}}=95 \%, \mathrm{Ns}=1.36\right.$ in ethanol $)$ were employed as the fluorescence standards.

Iron oxides were prepared through chemical precipitation. In brief, $0.27 \mathrm{~g}$ of ferric chloride and $0.10 \mathrm{~g}$ of ferrous chloride in $25 \mathrm{~mL}$ of distilled water were added with $4.5 \mathrm{~mL}$ of ammonium hydroxide. Iron oxide $@ \mathrm{mSiO}_{2}$ was prepared by mixing $25 \mathrm{~mL}$ of a solution containing $0.15 \mathrm{~g}$ of CTAB, $0.05 \mathrm{~g}$ of iron oxide, $0.15 \mathrm{~mL}$ of TEOS, $2.4 \mathrm{~mL}$ of ethanol, and $1.8 \mathrm{~mL}$ of ammonium hydroxide solution ( $28 \%$ ). Iron oxide @ $\mathrm{mSiO}_{2}$ was subjected to amination by mixing $1 \mathrm{~mL}$ of 3-aminopropyl triethoxysilane and $1 \mathrm{ml}$ of $\mathrm{NH}_{4} \mathrm{OH}$. This mixture was coupled with $\mathrm{CD}_{\mathrm{b}}$ by mixing $1 \mathrm{~mL}$ of $\mathrm{CD}_{\mathrm{b}}\left(0.12 \mathrm{~g} \mathrm{~mL}^{-1}\right)$ with $0.5 \mathrm{~mL}$ of $0.3 \mathrm{M}$ EDC, $0.5 \mathrm{~mL}$ of $0.075 \mathrm{M} \mathrm{NHS}$, and $2 \mathrm{mg}$ of iron oxide @ $\mathrm{mSiO}_{2}$ for $4 \mathrm{~h}$. The coupling of various nanoparticles $\left(3.0 \times 10^{15}\right)$ with biomarker antibodies $\left(2 \mathrm{~mL}\right.$ of $\left.8.0 \times 10^{-8} \mathrm{M}\right)$ was through a reaction involving the combination of $0.023 \mathrm{~g}$ of NHS and $0.153 \mathrm{~g}$ of EDC with $10 \mathrm{~mL}$ of phosphate-buffered saline over $2 \mathrm{~h}$.

\subsection{Magnetic Fluorescence-Linked Immunoassay}

Figure 1 displays magnetofluorescent nanoparticles (iron oxide @ $\mathrm{mSiO}_{2}-\mathrm{CD}_{\mathrm{b}}$ ) that were labeled with anti-CEA and anti-TNF- $\alpha$ in a microplate well. A magnetic microplate was prepared by placing permanent magnets of rare earth $(13 \mathrm{~mm}$ in length and $6 \mathrm{~mm}$ in diameter) under the bottom of a microplate for particle reconcentration after mixing and washing. The magnetic field strength was $2.5 \pm 0.1 \mathrm{kG}$ at the bottom well of the microplate. The volume of each reactant solution was $100 \mu \mathrm{L}$. Various quantities of CEA and TNF- $\alpha$ were allowed to react with magnetofluorescent labeled nanoparticles for immunocomplex formation. The presence of complexes containing CEA and TNF- $\alpha$ was confirmed using fluorescence $\left(C D_{g}\right.$ and $\left.C D_{r}\right)$-labeled anti-CEA and anti-TNF- $\alpha$, respectively. Each step of reaction included mixing and reconcentration to remove unreacted species under a magnetic field. The numbers of magnetofluorescent, $\mathrm{CD}_{\mathrm{g}} @ \mathrm{mSiO}_{2}$, and $\mathrm{CD}_{\mathrm{r}} @ \mathrm{SiO}_{2}$ nanoparticles labeled with the antibody used in the sandwich reaction of magnetic fluorescence-linked immunoassays were $3.0 \times 10^{12}, 1.5 \times 10^{13}$, and $1.5 \times 10^{13}$, dispersed in $100 \mu \mathrm{L}$ of solutions, respectively.

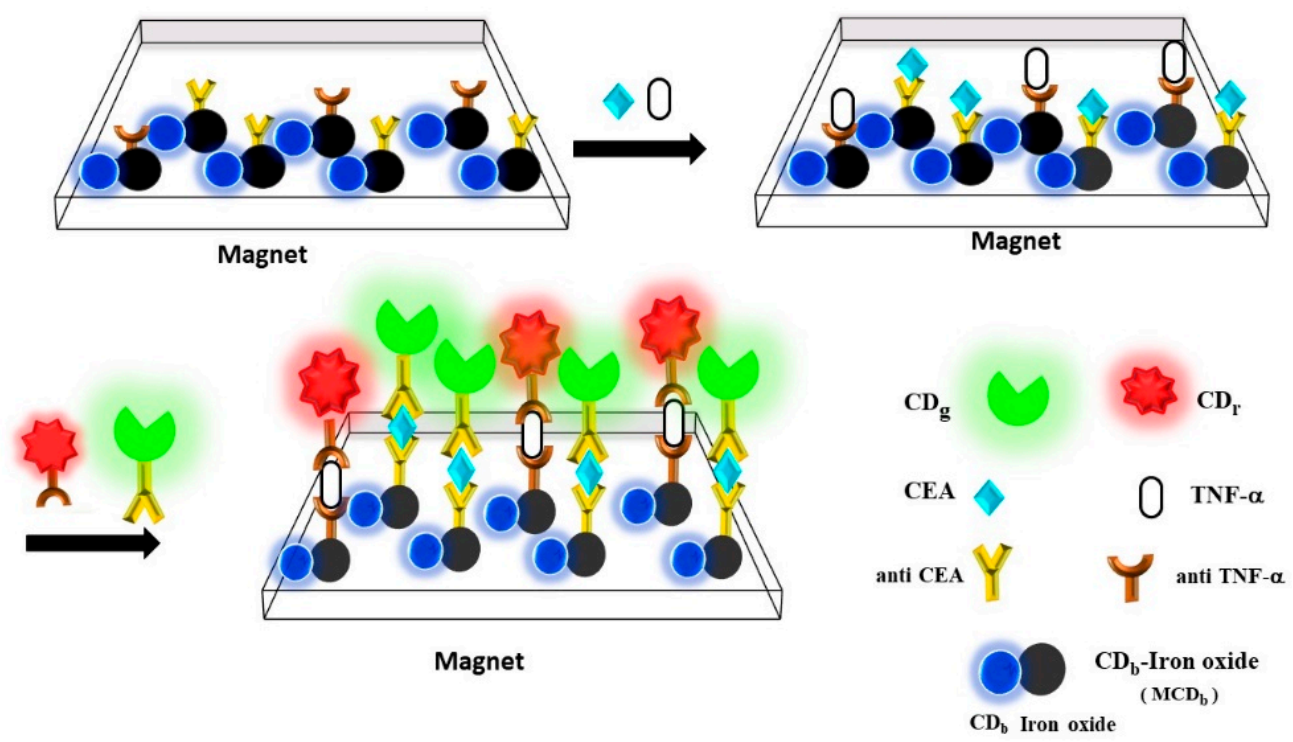

Figure 1. Schematic representation of the magnetic fluorescence-linked immunoassay with magnetofluorescent and fluorescent nanoparticles for the detection of CEA and TNF- $\alpha$. 
The reference plots of CEA and TNF- $\alpha$ were established by adding known concentrations of CEA and TNF- $\alpha\left(10^{-6} \mathrm{M}\right.$ to $\left.10^{-16} \mathrm{M}\right)$ to the sandwich reaction and then confirming the added concentrations by using anti-CEA-labeled and anti-TNF- $\alpha$-labeled CDs. The relative fluorescent intensity $\left(\mathrm{F} / \mathrm{F}_{\mathrm{O}}\right)$ is the ratio of the fluorescent intensity in the sandwich complex $(\mathrm{F})$ to the fluorescent intensity before the sandwich reaction $\left(\mathrm{F}_{\mathrm{o}}\right)$.

\section{Results and Discussion}

\subsection{Characterization of Nanoparticles}

The preparation of $\mathrm{CD}_{\mathrm{s}}$ from modified pine needles through microwave irradiation is displayed in the Scheme 1. The reaction times for all the $\mathrm{CD}_{\mathrm{s}}$ were less than $10 \mathrm{~min}$. The reaction temperature ranged from 180 to $220^{\circ} \mathrm{C}$ and the optimal reaction temperature for $\mathrm{CD}_{\mathrm{b}}$ and $\mathrm{CD}_{\mathrm{g}}$ was $220^{\circ} \mathrm{C}$. The relative fluorescent intensity (FI) was used to optimize the experimental conditions. Figure S1 shows the optimization of reaction temperature for a fixed time and reaction time for a fixed temperature. The sizes of $C D_{b}, C D_{g}$, and $C D_{r}$ nanoparticles were $3.0 \pm 0.2,4.0 \pm 1.5$, and $5.5 \pm 1.9 \mathrm{~nm}$, respectively (Figure S2). Figure S3 presents the infrared spectra of the $\mathrm{CD}_{\mathrm{s}}$. The three types of $\mathrm{CD}_{\mathrm{s}}$ exhibited absorption peaks at 1070, 1650, and $3400 \mathrm{~cm}^{-1}$ (ascribed to $\mathrm{C}-\mathrm{O}, \mathrm{C}=\mathrm{O}$, and $\mathrm{O}-\mathrm{H}$ stretching, respectively), indicating the presence of carboxylic acid. The absorption peaks at 2981 and $2897 \mathrm{~cm}^{-1}$ corresponded to the $\mathrm{C}-\mathrm{H}$ vibration of $\mathrm{CD}_{\mathrm{b}}$ and $\mathrm{CD}_{\mathrm{g}}$ nanoparticles, respectively. The emission wavelengths depended on the excitation wavelengths for the CDs. The excitation wavelength (Ex) range of $C D_{b}$ was $320-360 \mathrm{~nm}$ and that of $C D_{g}$ and $C D_{r}$ was $400-450 \mathrm{~nm}$. The emission wavelength of the maximal intensity changed marginally for each $\mathrm{CD}$ as shown in Figure 2a. The maximal emission intensities were optimized using appropriate excitation wavelengths. Specifically, the optimal emission wavelengths of $C D_{b}, C D_{g}$, and $\mathrm{CD}_{\mathrm{r}}$ were 400,510 , and $680 \mathrm{~nm}$, respectively, under excitation wavelengths of 320,410 , and $410 \mathrm{~nm}$, respectively. Figure $2 \mathrm{~b}$ shows UV-vis absorption spectra of the three types of $\mathrm{CD}_{\mathrm{s}}$ in PBS. The excitation wavelengths of 320,410 , and $410 \mathrm{~nm}$ in fluorescence from $\mathrm{CD}_{\mathrm{s}}$ were not the maximal absorption in the absorption spectra region of $C_{S}$ in UV-vis spectra. The excitation wavelengths were optimized by the maximal fluorescent intensity as shown in Figure 2a,b. We know that there are some intrinsic fluorescence materials in the pine needles, but we can not discern and isolate exactly from the overall emitting properties due to their complex components. Figure 3 a depicts the optimal emission spectra of the three types of $C D_{s} . C D_{b}$ was used for the magnetofluorescent reaction, and $C D_{g}$ and $C D_{r}$ were used to detect the sandwich detection. The $\mathrm{QY}_{\mathrm{s}}$ of $\mathrm{CD}_{\mathrm{b}}, \mathrm{CD}_{\mathrm{g}}, \mathrm{CD}_{\mathrm{r}}, \mathrm{CD}_{\mathrm{g}} @ \mathrm{mSiO}_{2}$, and $\mathrm{CD}_{\mathrm{r}} @ \mathrm{mSiO}_{2}$ were calculated to be $5.2,4.3,3.8,2.7$, and $3.4 \%$, respectively. The fluorescent intensities of the three types of $\mathrm{CD}_{\mathrm{s}}$ decreased by $<2.5 \%$ over 6 weeks, indicating that they were relatively stable. The reaction time was less than $10 \mathrm{~min}$. Notably, CDs were all fabricated from modified pine needle sources using microwave assistance and can be termed in the green synthesis category with an environmentally friendly feature.

The particle sizes of iron oxide, iron oxide@ $\mathrm{mSiO}_{2}, \mathrm{CD}_{\mathrm{g}} @ \mathrm{mSiO}_{2}$, and $\mathrm{CD}_{\mathrm{r}} @ \mathrm{mSiO}_{2}$, were $13,45,40$, and $40 \mathrm{~nm}$. Figure $3 \mathrm{c}$ s depicts TEM images of iron oxide, iron oxide $@ \mathrm{mSiO}_{2}$, and $\mathrm{CD}_{\mathrm{g}} @ \mathrm{mSiO}_{2}$. The fluorescent intensities of $\mathrm{CD}_{\mathrm{b}}$ decrease with a marginal change of emission maximum as a modification with iron oxide $@ \mathrm{mSiO}_{2}$ nanoparticles and antibodies (Figure 3b). The magnetic susceptibility of the magnetofluorescent nanoparticles was $27 \mathrm{emu} \mathrm{g}^{-1}$. The magnetic susceptibility value is much larger than those of literature (usually $<10 \mathrm{emu} \mathrm{g}^{-1}$ ) and is more useful for separation application. Magnetofluorescent nanoparticles maintained good magnetic and fluorescent properties for analytical applications. 


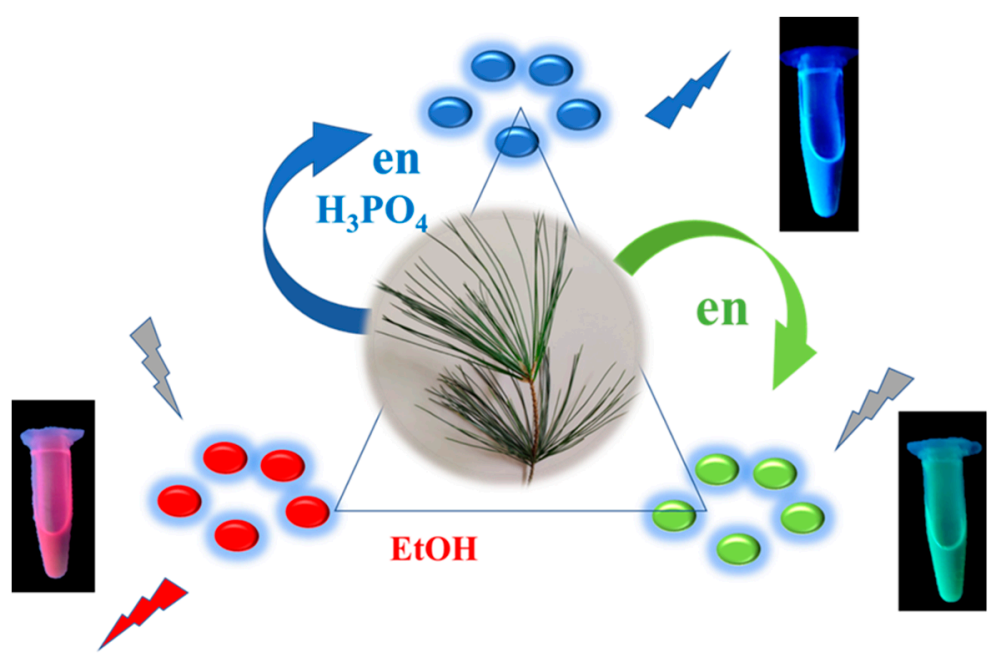

Scheme 1. Preparation for various $\mathrm{CD}_{\mathrm{s}}$.

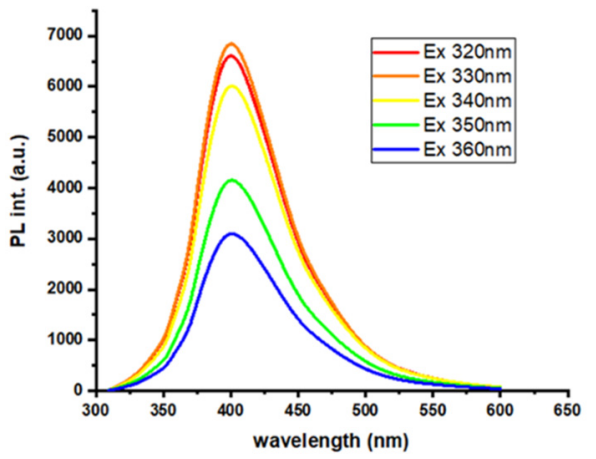

(a-CDb)

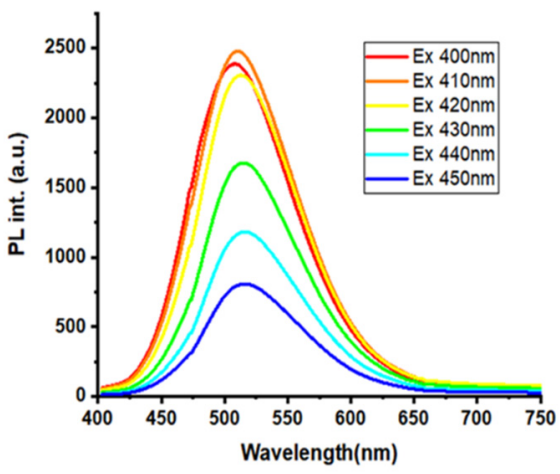

(a-CDg)

(a)

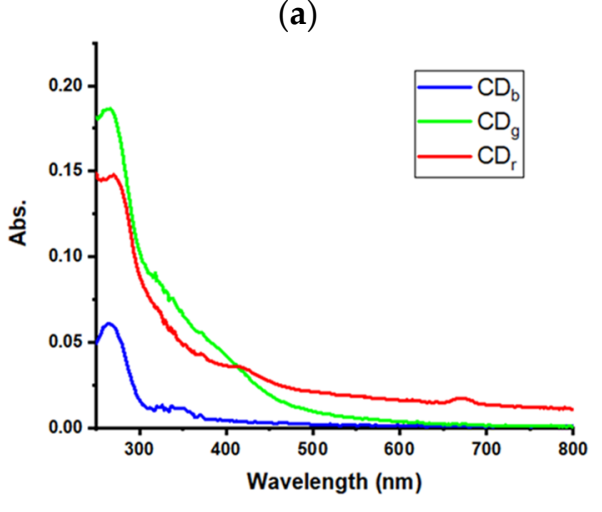

(b)

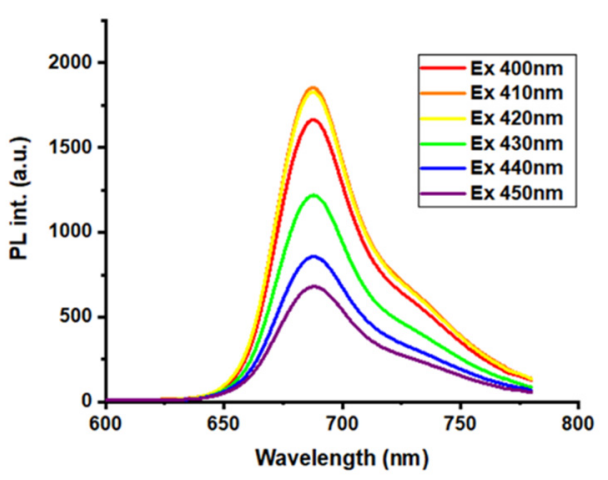

(a-CDr) 
was used as F. The relative fluorescent intensity and concentrations of CEA and TNF- $\alpha$ exhibited the $S$ shape characteristic of the sandwich immunoassay reaction. The linear range of CEA was $5.0 \times 10^{-13} \mathrm{M}\left(9 \mathrm{pg} \mathrm{mL}^{-1}\right)$ to $1.0 \times 10^{-10} \mathrm{M}\left(18 \mathrm{ng} \mathrm{mL}^{-1}\right)$ and the linear range of TNF- $\alpha$ was $5.0 \times 10^{-12} \mathrm{M}\left(8.5 \mathrm{pg} \mathrm{mL}^{-1}\right)$ to $1.0 \times 10^{-9} \mathrm{M}\left(17 \mathrm{ng} \mathrm{mL}^{-1}\right)$. The detection limits of CEA and TNF- $\alpha$ were $3.1 \mathrm{pg} \mathrm{mL}^{-1}$ and $2.8 \mathrm{pg} \mathrm{mL}^{-1}$, respectively. Table 1 presents a comparison of the detection limit and linear range obtained herein and in other studies [20-26]. The table contains one calorimetric method [25], two nanoparticle methods [20,23], and four electrochemical methods [21,22,24,26] from recent literature for comparison. The present method has a lower detection limit and wider linear range for CEA and TNF- $\alpha$ than do the compared approaches. The selectivity of the present method was tested by replacing CEA and TNF- $\alpha$ with $10^{-10} \mathrm{M}$ of immunoglobulin $\mathrm{G}$, hemoglobin, and ovalbumin in the sandwich reaction. The relative fluorescence intensities of these proteins were negligible (all $<0.1$, with no effect on the reference plots).

Table 1. Comparison of detection limit and linear range for CEA and TNF- $\alpha$.

\begin{tabular}{|c|c|c|c|c|}
\hline Biomarker & Literature & $\begin{array}{l}\text { Detection Limit } \\
\quad\left(\mathrm{ng} \mathrm{mL}^{-1}\right)\end{array}$ & $\begin{array}{l}\text { Linear Range } \\
\left(\text { (ng } \mathrm{mL}^{-1}\right)\end{array}$ & Ref. \\
\hline \multirow[t]{5}{*}{ CEA } & Sens. Actuator. B chem. 2021, 342, 130075 & 0.013 & $0.05-40$ & [20] \\
\hline & Anal. Chem. 2021, 93, 2916-2925 & 0.094 & $0.2-50$ & [21] \\
\hline & ACS Apple Nano Mater. 2020, 3, 3449-3458 & 0.0054 & $0.03-6$ & {$[22]$} \\
\hline & J Colloid Interface Sci. 2021, 601, 50-59 & 0.00352 & $0.05-40$ & [23] \\
\hline & This study & 0.0031 & $0.009-18$ & \\
\hline \multirow[t]{4}{*}{ TNF- $\alpha$} & Sens. Actuator. B chem. 2021, 336, 129747 & 0.005 & $0.005-0.20$ & [24] \\
\hline & Bios. Bioelectron. 2019, 126, 82-87 & 0.014 & $0.014-2.0$ & [25] \\
\hline & Sensor 2021, 20, 2857 & 0.078 & $0.1-100$ & [26] \\
\hline & This study & 0.0028 & $0.0085-17$ & \\
\hline
\end{tabular}

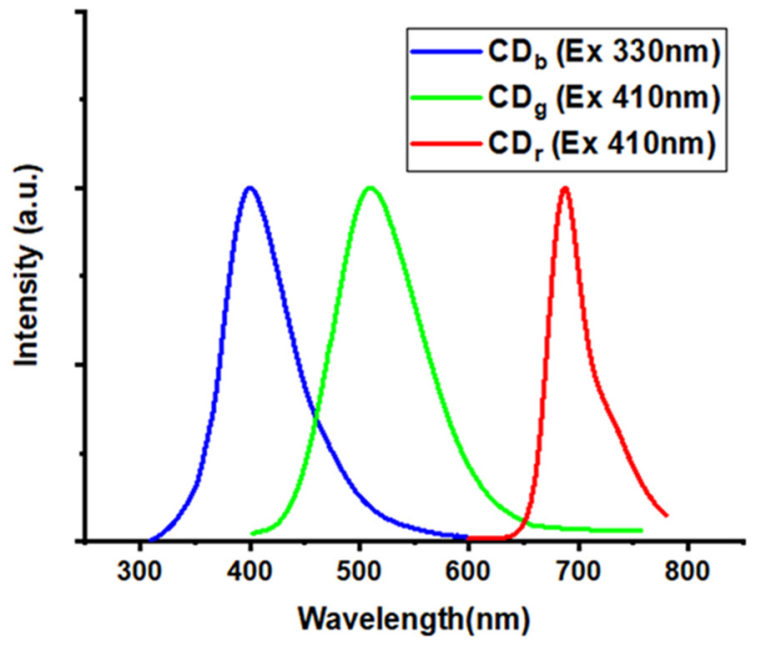

(a)

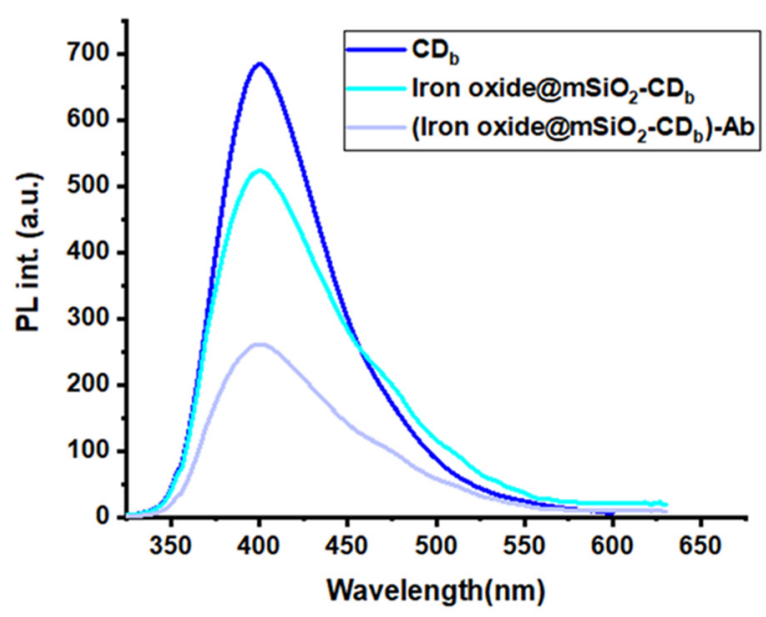

(b)

Figure 3. Cont. 


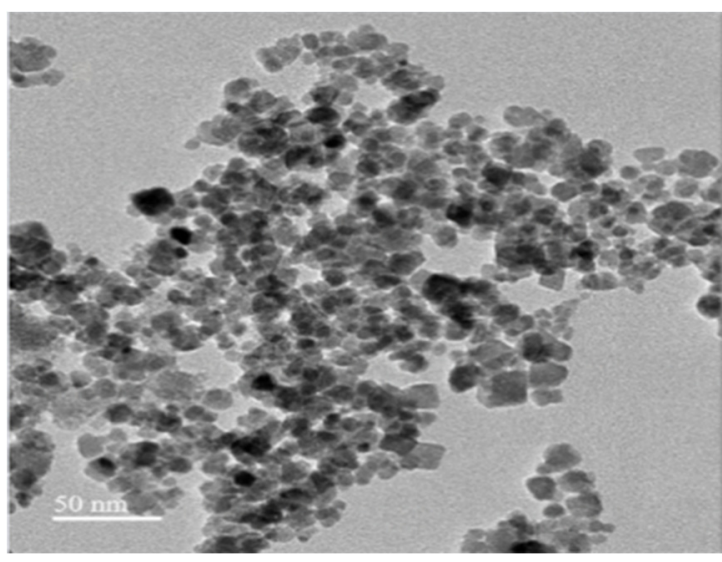

c-Iron oxide

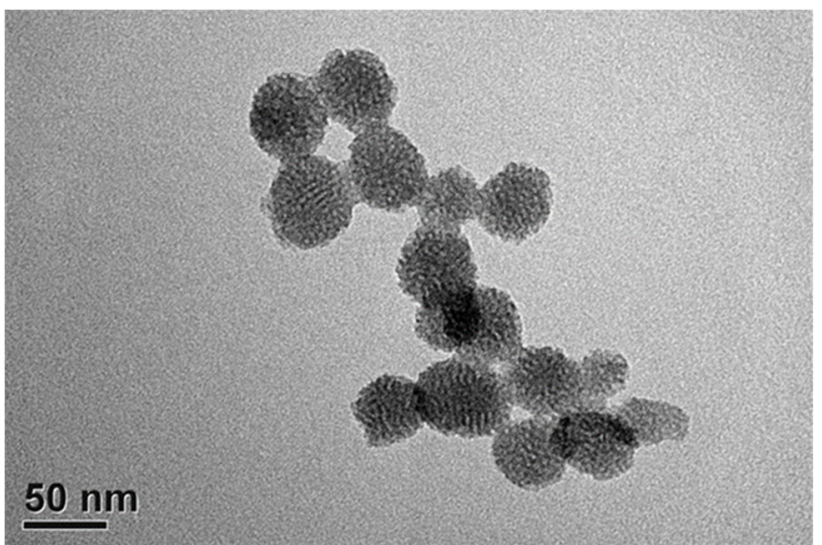

c-Iron oxide @ $\mathrm{mSiO}_{2}$

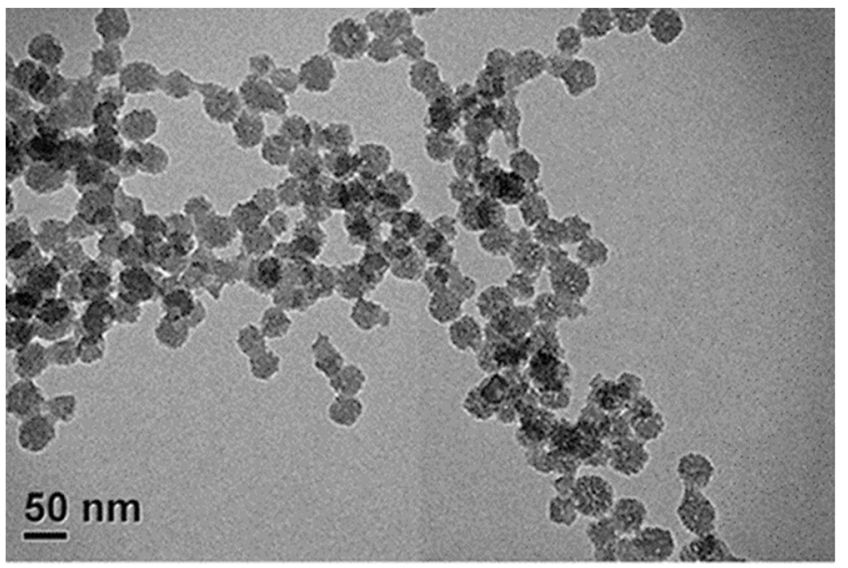

c-CDg@m-SiO2

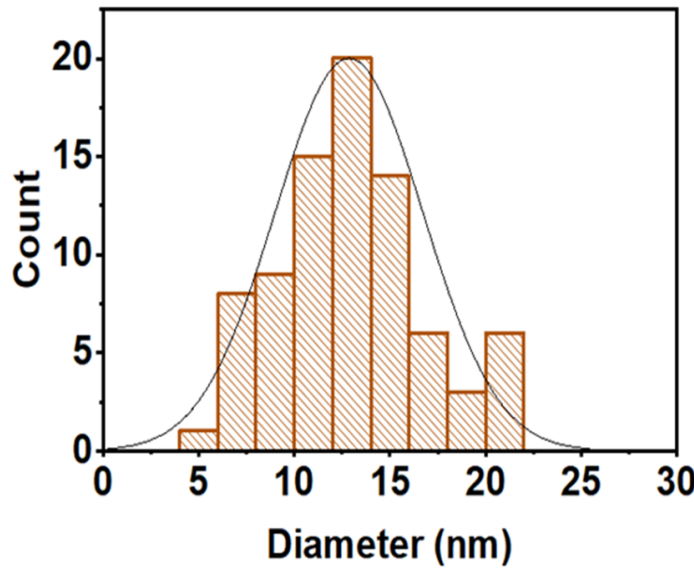

c-Iron oxide particle size distribution

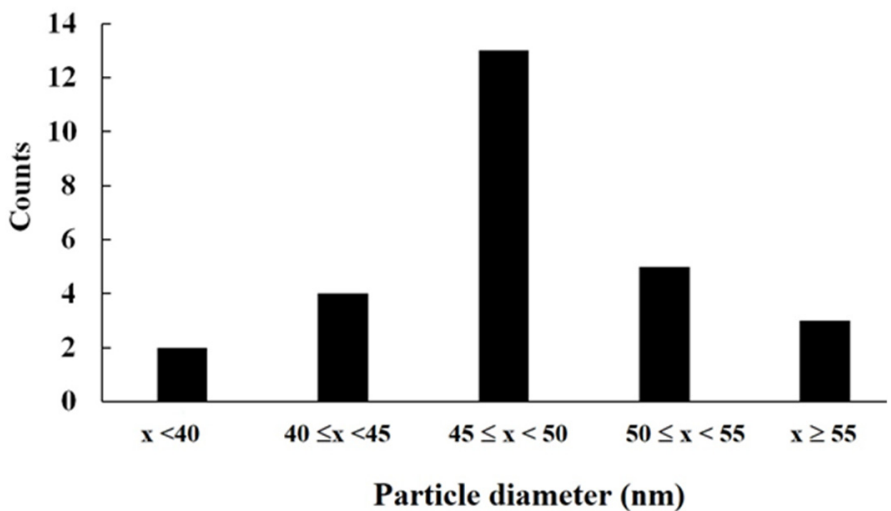

c-Iron oxide @ $\mathrm{mSiO}_{2}$ particle size distribution

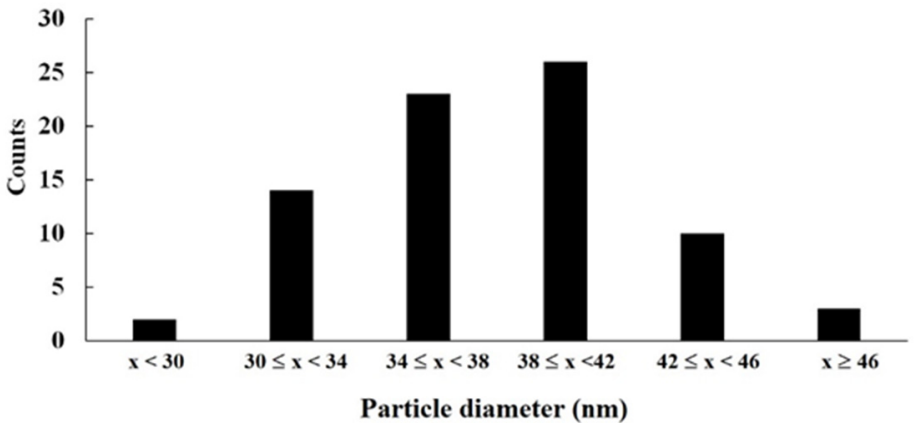

c-CDg@mSiO2 particle size distribution

(c)

Figure 3. (a) Optimal emission spectra of the three types of $\mathrm{CD}_{\mathrm{s}},(\mathbf{b})$ variations in the fluorescence intensity of $C D_{b}$ with each modification step, and (c) transmission electron microcopy images of iron oxide, iron oxide @ $\mathrm{mSiO}_{2}$, and $\mathrm{CDg} @ \mathrm{mSiO}_{2}$.

Table S1 presents a comparison of the proposed method with ELISA on the detection of CEA and TNF- $\alpha$ in spiked serum samples with three concentrations. The average (range) of the differences between the actual concentrations of the spiked samples and the concentrations detected using the proposed method was 5.6\% (2.5-10\%). The average (range) of the differences in the concentrations detected using the proposed method and ELISA was $7.9 \%(5.2-12 \%)$. These results indicate that both measurements from the proposed method and ELISA were within acceptable experimental error margins. Magnetic fluorescence- 
linked immunoassay has several advantages over those of ELISA. First, the antibody on the microplate has more available binding sites and a more efficient reaction with analytes without limitations of planar fixation. Second, magnetic nanoparticles can have faster separation and reconcentration under a magnetic field. Third, fluorescence detection has the potential for lower detection limits. The running time of the proposed method was approximately $25 \mathrm{~min}$, one-third of the typical running time for ELISA. The high sensitivity of the proposed method originates from the efficient mixing of nanoparticles and its short running time of the sandwich reaction can be attributed to the magnetic concentrations used. The automation of this method is expectable for high throughput. The proposed method enables the rapid, sensitive, and cost-effective detection of biomarkers by using $\mathrm{CD}_{\mathrm{s}}$ prepared from modified pine needles with ecologically friendly sources.
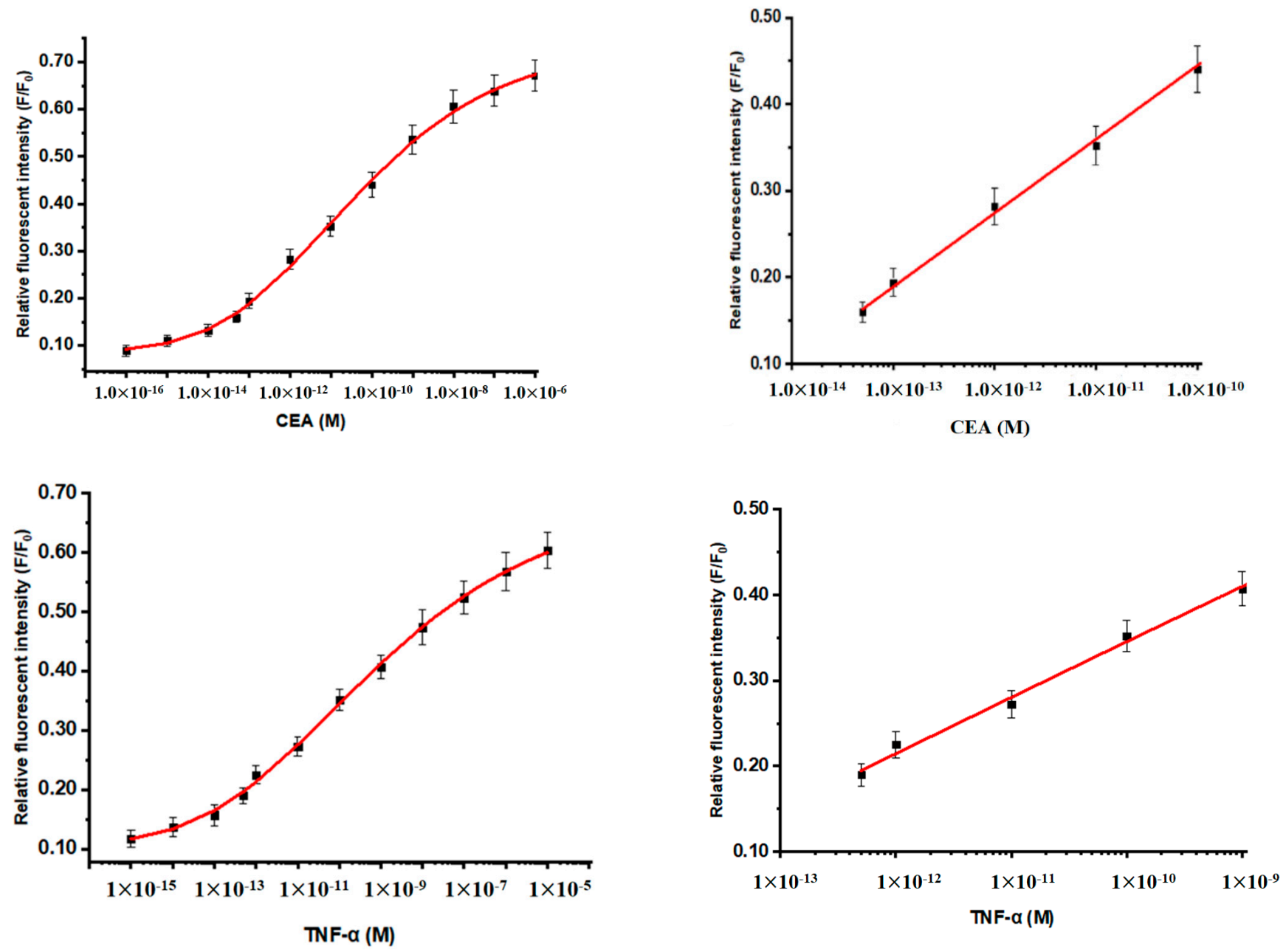

Figure 4. Reference plots of CEA and TNF- $\alpha$ for the magnetic fluorescence-linked immunoassay.

\section{Conclusions}

In this study, $\mathrm{CD}_{\mathrm{s}}$ with blue, green, and red emissions were rapidly prepared from pine needles with some modifications. The prepared CDs can be employed in the rapid, simple, green, and economical detection of biomarkers for chemical analysis. Magnetic fluorescence-linked immunoassay with fluorescent CDs from modified pine needles was demonstrated for biomarker detection. The measurements of spiked biomarkers from the proposed method and ELISA were consistent and within acceptable experimental error margins. Compared with ELISA and other methods used in the literature, the magnetic fluorescence-linked immunoassay exhibited faster detection with a lower detection limit 
and/or wider linear range for CEA and TNF- $\alpha$ biomarkers. This method has the potential as an alternative method to ELISA for biomarker detections.

Supplementary Materials: The following supporting information can be downloaded at: https: / / www.mdpi.com/article/10.3390/nano12010066/s1. Table S1 Comparison of the Concentrations of CEA and TNF- $\alpha$ Detected Under the Proposed Method and the ELISA. Figure S1 The optimization of reaction temperature for a fixed time and reaction for a fixed temperature. Figure S2 TEM photographs of $C D_{b}, C D_{g}$, and $C D_{r}$ nanoparticles. Figure 33 . Infrared spectra of the three types of CDs.

Author Contributions: H.T.: Writing-review \& editing, conceptualization, K.C. and W.L.: experiment and data curation, C.B.F.: Writing-review \& editing, supervision, conceptualization, and funding acquisition. All authors have read and agreed to the published version of the manuscript.

Funding: This work was supported by the Ministry of Science and Technology in Taiwan (Grant MOST-108-2113-M-260-009).

Institutional Review Board Statement: Not applicable.

Informed Consent Statement: Not applicable.

Data Availability Statement: Data can be available upon request from the authors.

Acknowledgments: The authors would like to thank Lokesh Bettada from NCNU for his technical assistance.

Conflicts of Interest: The authors declare that they have no known competing financial interests or personal relationships that could have appeared to influence the work reported in this paper.

\section{References}

1. Semeniuk, M.; Yi, Z.; Poursorkhabi, V.; Tjong, J.; Jaffer, S.; Lu, Z.H.; Sain, M. Future Perspectives and Review on Organic Carbon Dots in Electronic Applications. ACS Nano 2019, 13, 6224-6255. [CrossRef] [PubMed]

2. Shi, X.; Wei, W.; Fu, Z.; Gao, W.; Zhang, C.; Zhao, Q.; Deng, F.; Lu, X. Review on carbon dots in food safety applications. Talanta 2019, 194, 809-821. [CrossRef] [PubMed]

3. Long, C.; Jiang, Z.; Shangguan, J.; Qing, T.; Zhang, P.; Feng, B. Applications of carbon dots in environmental pollution control: A review. Chem. Eng. J. 2021, 406, 126848. [CrossRef]

4. Li, S.; Zhang, Z. Recent advances in the construction and analytical applications of carbon dots-based optical nanoassembly. Talanta 2021, 223, 121691. [CrossRef] [PubMed]

5. Fedorenko, S.; Stepanov, A.; Bochkova, O.; Kholin, K.; Dovjenko, A.; Zairov, R.; Nizameev, I.; Gerasimova, T.; Strelnik, I.; Voloshina, A.; et al. Tailoring of silica nanoarchitecture to optimize $\mathrm{Cu}_{(2-x)} \mathrm{S}$ based image-guided chemodynamic therapy agent. Colloids Surf. A 2021, 626, 126996. [CrossRef]

6. Zairov, R.R.; Dovzhenko, A.P.; Sarkanich, K.A.; Nizameev, I.R.; Luzhetskiy, A.V.; Sudakova, S.N.; Podyachev, S.N.; Burilov, V.A.; Vatsouro, I.M.; Vomiero, A.; et al. Single excited dual band luminescent hybrid carbon dots-terbium chelate nanothermometer. Nanomaterials 2021, 11, 3080. [CrossRef] [PubMed]

7. Kamyshnikov, A.G.; Zaripov, A.T.; Beregovoy, A.N.; Ibatullin, R.R.; Zairov, R.R.; Dovzhenko, A.P. Carbon quantum dots used as tracers in ecological, hydrogeologicalmonitoring and reservoir management. Oil Ind. J. 2021, 7, 44-48.

8. Khatamian, N.; Soltani, M.; Shadan, B.; Neamati, A.; Tabrizi, M.H.; Hormozi, B. Pinus morrisonicola needles essential oil nanoemulsions as a novel strong antioxidant and anticancer agent. Inorg. Nano-Met. Chem. 2021, 5, 1-9. [CrossRef]

9. Sameiyan, E.; Hayes, A.W.; Karimi, G. The effect of medicinal plants on multiple drug resistance through autophagy: A review of in vitro studies. Eur. J. Pharmacol. 2019, 852, 244-253. [CrossRef]

10. Chen, G.H.; Li, Y.C.; Lin, N.H.; Kuo, P.C.; Tzen, J. Characterization of Vasorelaxant Principles from the Needles of Pinus morrisonicola Hayata. Molecules 2018, 23, 86. [CrossRef]

11. Cheng, M.C.; Chang, W.H.; Chen, C.W.; Li, W.W.; Tseng, C.Y.; Song, T.Y. Antioxidant Properties of Essential Oil Extracted from Pinus morrisonicola Hay Needles by Supercritical Fluid and Identification of Possible Active Compounds by GC/MS. Molecules 2015, 20, 19051-19065. [CrossRef]

12. Singh, R.K.; Kuma, R.; Singh, D.P.; Savu, R.; Moshkalev, S.A. Progress in microwave-assisted synthesis of quantum dots for bioapplications: A review. Mater. Today Chem. 2019, 12, 282-314. [CrossRef]

13. Yang, G.; Park, S.J. Conventional and microwave hydrothermal synthesis and application of functional materials: A review. Materials 2019, 12, 1177. [CrossRef]

14. Borrebaeck, C.A.K. Precision diagnostics: Moving towards protein biomarker signatures of clinical utility in cancer. Nat. Rev. Cancer 2017, 17, 199-204. [CrossRef] [PubMed]

15. O'Connor, J.P.B.; Waterton, J.C. Imaging biomarker roadmap for cancer studies. Nat. Rev. Clin. Oncol. 2017, 14, 169-186. [CrossRef] 
16. Tsai, H.Y.; Chan, J.R.; Li, Y.C.; Cheng, F.C.; Fuh, C.B. Determination of Hepatitis B Surface Antigen Using Magnetic Immunoassays in a Thin Channel. Biosens. Bioelectron. 2010, 25, 2701-2705. [CrossRef]

17. Yang, S.F.; Gao, B.Z.; Tsai, H.Y.; Fuh, C.B. Detection of c-reactive protein based on a magnetic immunoassay by using functional magnetic and fluorescent nanoparticles in microplates. Analyst 2014, 139, 5576-5581. [CrossRef]

18. Tsai, H.Y.; Lin, W.M.; Chuang, M.C.; Lu, Y.S.; Fuh, C.B. Multifunctional nanoparticles for protein detections in thin channels. Biosens. Bioelectron. 2017, 90, 153-158. [CrossRef] [PubMed]

19. Tsai, H.Y.; Wu, H.H.; Chou, B.C.; Li, C.S.; Gau, B.Z.; Lin, Z.Y.; Fuh, C.B. A magneto-microfluidic platform for fluorescence immunosensing using quantum dot nanoparticles. Nanotechnology 2019, 3, 505101. [CrossRef]

20. Hou, L.; Huang, J.; Liu, S.; Lin, T.; Zhao, S. Magneto-controlled fluorescent immunosensor for sensitive determination of biomarker via three-dimensional AuNCs/liposome networks. Sens. Actuators B Chem. 2021, 342, 130075. [CrossRef]

21. Yu, Z.; Cai, G.; Liu, X.; Tan, D. Pressure-Based Biosensor Integrated with a Flexible Pressure Sensor and an Electrochromic Device for Visual Detection. Anal. Chem. 2021, 93, 2916-2925. [CrossRef]

22. Zheng, J.; Wang, J.; Song, D.; Xu, J.; Zhang, M. Electrochemical aptasensor of carcinoembryonic Antigen Based on concanavalin A-functionalized magnetic copper silicate carbon microtubes and gold-nanocluster-assisted signal amplification. ACS Appl. Nano Mater. 2020, 3, 3449-3458. [CrossRef]

23. Gao, J.; Liu, H.; Wu, K.; Yan, J.; Li, H.; Yang, R.; Tong, C.; Pang, L.; Li, J. Biocatalyst and colorimetric biosensor of carcinoembryonic antigen constructed via chicken egg white-copper phosphate organic/inorganic hybrid nanoflowers. J. Colloid Interface Sci. 2021, 601, 50-59. [CrossRef] [PubMed]

24. Shen, Z.; Ni, S.; Yang, W.; Sun, W.; Yang, G.; Liu, G. Redox probes tagged electrochemical aptasensing device for simultaneous detection of multiple cytokines in real time. Sens. Actuators B. Chem. 2021, 336, 129747. [CrossRef]

25. Baria, S.M.I.; Reisb, L.G.; Nestorova, G.G. Calorimetric sandwich-type immunosensor for quantification of TNF- $\alpha$. Biosens. Bioelectron. 2019, 126, 82-87. [CrossRef]

26. Arya, S.K.; Estrela, P. Electrochemical ELISA protein biosensing in undiluted serum using a polypy role based platform. Sensors 2020, 20, 2857. [CrossRef] 